\title{
Dynamic Analysis of Hydraulic Support with Single Clearance
}

\author{
Qingliang Zeng1,2 - Yangyang Li ${ }^{1}$ - Yang Yang1,* \\ ${ }^{1}$ Shandong University of Science and Technology, College of Mechanical \& Electronic Engineering, China \\ ${ }^{2}$ Shandong Normal University, China
}

Hydraulic support is a complex parallel mechanism composed of multiple kinematic pairs. In the work of hydraulic support, clearances between kinematic pairs are inevitable, which lead to the deterioration of the support's working performance, and may even affect support's normal work in serious cases. To study the influence of clearances on hydraulic support and simultaneously avoid the mutual interference between different clearances, the normal and tangential force models of kinematic pairs with clearance are established, based on the Lankarani-Nikravesh contact force model and the Coulomb friction model. Furthermore, the dynamic model of the hydraulic support with single clearance is established by adding a clearance between the rear link and base and, according to the dynamic model of the hydraulic support, the research about the influence of clearance on the movement and force of hydraulic support is carried out, which proves the need to study the clearance of hydraulic support. Moreover, the influence of clearance, clearance size, and different oil inlet drive modes of front and rear columns on the stability of hydraulic support are analysed, and then the change of hydraulic support posture caused by clearance and clearance size is considered. The results show that clearance causes the movement and force of the rear link to fluctuate, which affects the stability of the hydraulic support. The clearance size affects the fluctuation degree of the movement and force, which is an important factor in the instability of hydraulic support. Also, the hydraulic support posture is changed by the clearance and clearance size. Different column oil inlet drive modes have different impacts on the clearance and have different effects on the stability of hydraulic support.

\section{Keywords: dynamic analysis, kinematic pair clearance, clearance size, hydraulic support posture}

\section{Highlights}

- Taking the hydraulic support as the research subject, the dynamic analysis of the hydraulic support with clearance between the rear link and the base is carried out based on the Lankarani-Nikravesh model.

- The dynamic performance of hydraulic support with clearance and without clearance has been compared, proving the necessity of research on hydraulic support clearance.

- The dynamic performance of hydraulic support with clearance under different clearance size and oil inlet drive mode has been compared, and the influence of clearance size and oil inlet drive mode on hydraulic support has been analysed.

- The influence of clearance and clearance size on the posture of hydraulic support has been studied, and the influence of posture on the working performance of hydraulic support has been analysed.

\section{INTRODUCTION}

As important supporting equipment in coal mining, hydraulic support has always been a research hotspot in the coal industry worldwide. With the introduction of the concept of intelligent mining, hydraulic support has begen to develop in the direction of intelligent posture monitoring [1], intelligent working face perception [2] and [3], intelligent control [4] and [5], etc. Moreover, support adaptability analysis [6] and load-bearing strength analysis [7] based on experimental verification and virtual simulation also tend to the working conditions, and the analysis and research of the new hydraulic support have also made progress [8]. As an inevitable component in the production process of hydraulic support, the impact of clearance on the working performance of hydraulic support is difficult to eliminate. Therefore, it is essential to study the influence of clearance on hydraulic support for improving the working performance and the stability of the hydraulic support.
However, the research on the dynamic analysis of the hydraulic support with clearance is scarce at present, and it is urgent that it be carried out.

The key point of the dynamic analysis of mechanism with clearance is the model of the establishing contact force. At present, according to the different descriptions of the state between shaft and bearing, three kinds of contact force models are proposed: the continuous contact model, the two-state model, and the three-state model. Based on the contact force models, many research studies have been carried out by domestic and foreign scholars. Flores [9] and Flores et al. [10] studied the crank and analysed the influence of revolute pair with clearance on crank slider through numerical analysis and experiment. $\mathrm{Li}$ et al. [11] established a dynamic model of the spring operating mechanism based on the continuous contact model and obtained the influence of clearance on the movement state through a numerical solution. Pereira et al. [12] studied the influence of spherical and cylindrical contact force models on the crank slider 
revolute pairs, which further improved the validity of the modelling of the revolute pairs. Li et al. [13] established a dynamic model of a connecting rod with clearance between pairs based on the two-state model and analysed the influence of different factors on the movement and force of the mechanism. Li et al. [14] established the kinematics and dynamics model of the 5-prismatic-spherical-spherical/universalprismatic-universal (5-PSS/UPU) parallel mechanism with spherical pair clearance through the two-state model, and analysed the impact of clearance size on the dynamic performance of the system. Erkaya [15[ and [16] used the nonlinear spring damping model to conduct kinematics and dynamics analysis on the welding robot with clearance, and studied the impact of clearance on the movement error, vibration, and force of the welding robot. Bai et al. [17] established a new contact force model of planar linkage mechanism, and proposed a kinematics and dynamics optimization scheme of linkage structure to reduce the vibration peak caused by clearance. Wang et al. [18] and [19] proposed an improved normal contact force model and modified Coulomb friction model and took the crank slider and four-bar linkage mechanism as research objects to analyse the impact of clearance on the dynamic characteristics of the mechanism. Matekar and Fulambarkar [20] established a crank slider simulation model without clearance or adjustable clearance by Adams, analysed the impact of clearance on the slider displacement, and verified the simulation results through experimental devices. Tajaril et al. [21] established the mathematical model of the mechanical system by adding spherical clearance to a hexapod robot, obtained the impact of clearance on the position accuracy of the robot and verified the results through experiments. $\mathrm{Xu}$ et al. [22] studied the influence of clearance on the positional accuracy of the SCARA robot by establishing joint clearance model and experimental verification and analysed the determinants of clearance error. Gu et al. [23] carried out a dynamic analysis on the space manipulator with clearance based on Lankarani-Nikravesh contact force model and obtained the influence of clearance on the output results of the manipulator. Huang et al. [24] considered both the clearance and flexibility of the mechanism, and established the dynamic model of the 3-revolute-revolute-revolute (3-RRR) parallel mechanism by Adams to analyse the influence of different clearance on the displacement and velocity of the mechanism. Hou et al. [25] established a flexible 3-revolute-spherical-revolute (3-RSR) parallel mechanism simulation model based on Adams, and discussed the dynamic characteristics of the system under different clearance types. Zhang and Zhang [26] proposed that a redundant drive 4-RRR mechanism could effectively control the joint clearance through kinematics and dynamics analysis of the 3-degree of freedom (3-DOF) redundant drive 4-RRR mechanism. Erkaya [27] established a dynamic simulation model and experimental device of the spatial slider-crank mechanism system with clearance, and obtained the influence of clearance size and driving speed on the vibration response of the system. Based on an experimental device, Erkaya

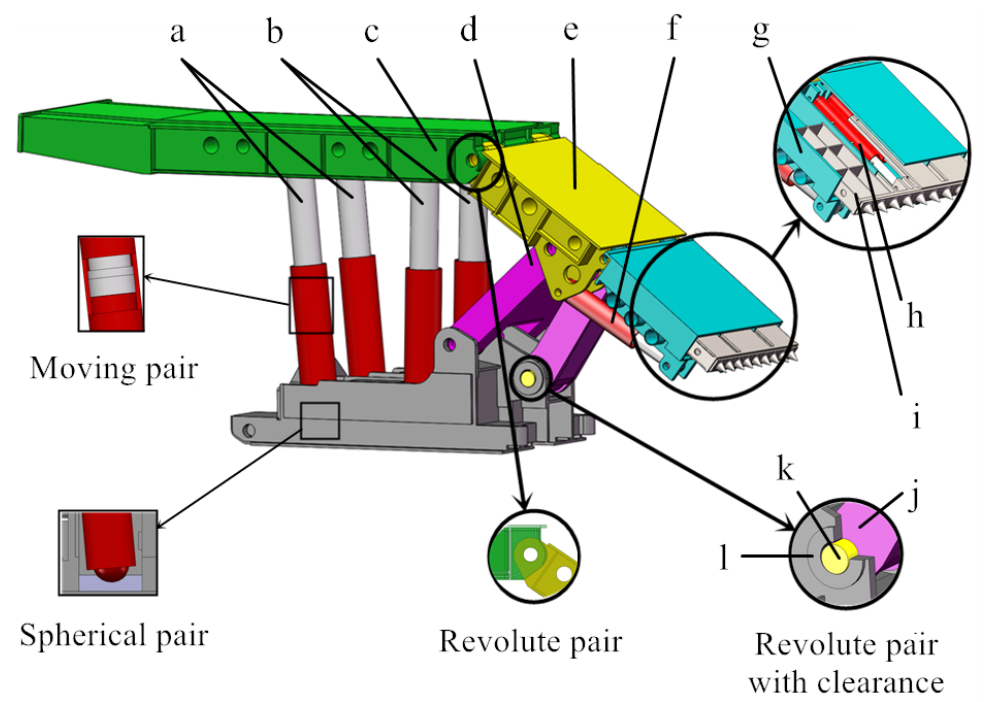

Fig. 1. Structure of four columns hydraulic support for top coal caving; a) front columns, b) rear column, c) top beam, d) front linkage, e) shield beam, f) tail beam jack, g) tail beam, h) plug plate jack, i) plug plate, j) rear linkage, $k$ ) shaft, and I) base 
[28] analysed the influence of clearance on the current fluctuation and power consumption of the system actuator, and designed a neural predictor to predict and evaluate the current. Chen et al. [29] established the planar model of hydraulic rock-breaker with multi clearance based on the Lankarani-Nikravesh model and Lagrange multiplier method, analysed the dynamic response of hydraulic rock-breaker and studied the influence of clearance size, friction and other factors on the dynamic characteristics of hydraulic rock-breaker. Tian et al. [30] compared and analysed the planar and spatial modelling methods of mechanical system with clearances, introduced the modelling methods of different types of dry and lubrication clearances, and summarized the previous clearance analysis and experiments. Edler et al. [31] developed a one-dimensional (1-D) simulation model of the progressive flow control and used in hydrostatic bearing to obtain a constant bearing clearance.

Previous studies mainly focus on the analysis of clearance, and the research object is mostly simple linkage mechanism, and research on construction machinery is less common. This paper will take the hydraulic support in coal mining as the research object, combined with the actual working situation, analyse the influence of the clearance on the working performance of the hydraulic support, and provide a new direction for further improving the working performance of the hydraulic support.

Hydraulic support is a complex parallel mechanism containing spherical pair, moving pair and revolute pair. In practical work, the normal operation of hydraulic support is restricted due to the unavoidable clearances. Fig. 1 is the structure diagram of the hydraulic support. It can be seen that the positions of support kinematic pair are different, as are the clearance forms of different kinematic pairs. Moreover, the kinematic pairs with clearance affect each other.

If all the clearances of hydraulic support are considered at the same time, it is difficult to describe the influence of each clearance accurately. Therefore, the research of hydraulic support with clearance should start from the single clearance, and the selection of the clearance position is also very important for the research. As a parallel mechanism driven by oil cylinder, the hydraulic support controls the movement of the top beam through the front columns and rear columns, and controls the movement of the tail beam and the plug plate through the tail beam jack and the plug plate jack. The four-bar linkage mechanism composed of front and rear linkages, shield beam and base, which simultaneously affect the position change of top beam, tail beam and plug plate, which is the key to control the movement of the hydraulic support. Moreover, the rear linkage is the only single connected part containing the clearance of revolute pair in the hydraulic support, and it is an important part for the hydraulic support to bear the load. Therefore, the clearance between the rear linkage and the base is the best position to study the influence of single clearance on the hydraulic support. By establishing the dynamic model of hydraulic support with clearance between the rear linkage and base, this paper will discuss the influence of single clearance on the movement and force of hydraulic support, so as to provide theoretical and research basis for the subsequent research work of hydraulic support with clearance.

\section{MODELLING OF HYDRAULIC SUPPORT WITH SINGLE CLEARANCE}

\subsection{The State Model at Single Clearance}

The key point of analysing the mechanism with clearance is the establishment of a contact force model. In order to establish the contact force model between the rear linkage and base, the contact state of bearing and shaft should be described first. Fig. 2 is a simplified model of the clearance between the rear linkage and the base. In the ideal situation, the centre of shaft and bearing are in the same position; however, due to the existence of clearance, there is an eccentric distance between the shaft and the bearing in practical work. In the figure, $\mathrm{O}_{1}$ and $\mathrm{O}_{2}$ are the centre of the shaft and the bearing, respectively, and their radii are $R_{1}$ and $R_{2}$, so the clearance radius of shaft and bearing can be expressed as follows:

$$
c=R_{2}-R_{1} .
$$

Under the fixed coordinate system O-XY, the position vectors of $\mathrm{O}_{1}$ and $\mathrm{O}_{2}$ are $\mathbf{r}_{1}$ and $\mathbf{r}_{2}$ respectively, then the offset vector between shaft and bearing can be expressed as:

$$
\mathbf{e}=\mathbf{r}_{2}-\mathbf{r}_{1} .
$$

In addition, the offset distance between the shaft and bearing can be expressed as the norm of the offset vector, so the penetration depth between the shaft and bearing can be expressed as:

$$
\delta=e-c .
$$

According to Eq. (3), the movement state of shaft and bearing can be expressed by $\delta$, when $\delta>0$, the shaft and bearing are in collision state, and 


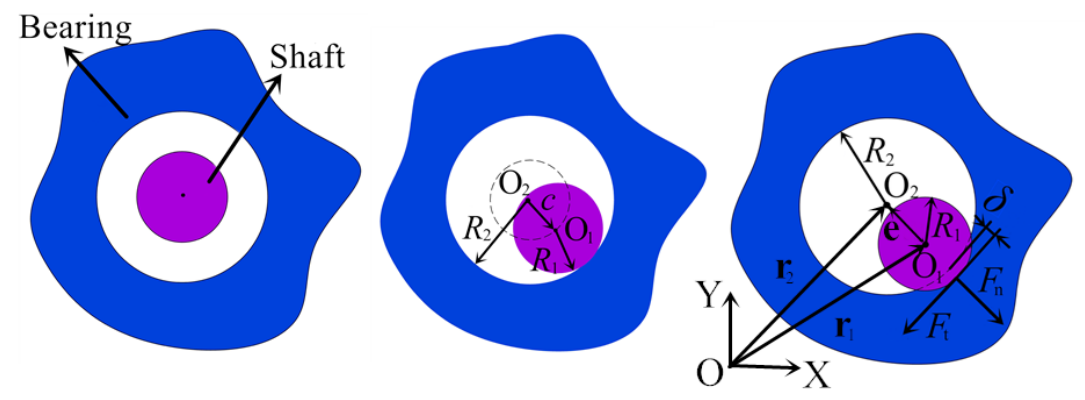

Fig. 2. Clearance simplification model of revolute pairs

the penetration depth is $\delta$; When $\delta=0$, the shaft and bearing are in a state of contact or separation. When $\delta<0$, the shaft and bearing are in a separate state; they both move freely without contact.

\subsection{Clearance Contact Force Model}

Contact force will be generated during the collision between shaft and bearing and can be simply decomposed into normal force and tangential force. The direction of the normal force is the normal direction of the contact surface, mainly the normal collision force between the shaft and bearing, while the tangential force is the tangent direction of the contact surface, mainly the tangential friction between the shaft and bearing.

After years of research, various researchers have proposed various models of normal contact force based on Hertz contact models. The Lankarani-Nikravesh contact force model takes into account the energy dissipation in the collision process and becomes a widely used nonlinear spring damping model in clearance research. According to the LankaraniNikravesh contact force model, the normal contact force $F_{\mathrm{n}}$ in the contact process can be expressed as:

$$
F_{\mathrm{n}}=K \delta^{n}+D v .
$$

In Eq. (4), $\delta$ is the penetration depth between shaft and bearing; $n$ is the force index, and $n=1.5$ for the contact between metals; $D$ is the damping coefficient of contact process; $v$ is the normal collision speed between shaft and bearing; $K$ is the stiffness coefficient of the contact process, and its equation is [32]:

$$
\begin{gathered}
K=\frac{4}{3 \pi\left(h_{1}+h_{2}\right)} \sqrt{\frac{R_{1} R_{2}}{R_{1}+R_{2}}}, \\
h_{i}=\frac{1-u_{i}^{2}}{\pi E_{i}}, \quad i=1,2 .
\end{gathered}
$$

In Eq. (5), $h_{1}$ and $h_{2}$ are the material coefficients of the contact object and the equation is Eq. (6), $u_{1}$ and $u_{2}$ are Poisson's ratio of the contact material, $E_{1}$ and $E_{2}$ are the elastic modulus of the contact material.

According to the different forms of friction, the tangential contact force model can be divided into a dry friction model and a lubrication friction model. The friction between the rear linkage and base belongs to dry friction, and the dry friction is generally modelled by the Coulomb friction model or the nonlinear friction model developed by domestic and foreign scholars. The nonlinear friction model proposed by Ambrósio based on the improvement of the Coulomb friction model is widely used, and its expression is as follows:

$$
F_{\mathrm{t}}=-\mu_{\mathrm{d}} c_{\mathrm{d}} F_{\mathrm{n}} \mathbf{t} .
$$

In Eq. (7), $\mu_{\mathrm{d}}$ is the sliding friction coefficient; $F_{\mathrm{n}}$ is the normal contact force; $v_{\mathrm{T}}$ is the tangential relative velocity between the shaft and bearing; $\mathbf{t}$ is the direction of tangential contact force; $c_{\mathrm{d}}$ is the dynamic correction coefficient, which is expressed as:

$$
c_{\mathrm{d}}=\left\{\begin{array}{cc}
0 & v_{\mathrm{T}} \leq v_{\mathrm{s}} \\
\frac{v_{\mathrm{T}}-v_{\mathrm{s}}}{v_{\mathrm{d}}-v_{\mathrm{s}}} & v_{\mathrm{s}}<v_{\mathrm{T}}<v_{\mathrm{d}} . \\
1 & v_{\mathrm{T}} \geq v_{\mathrm{d}}
\end{array}\right.
$$
values.

In Eq. (8), $v_{\mathrm{s}}$ and $v_{\mathrm{d}}$ are specific velocity limit

\section{DYNAMIC ANALYSIS OF HYDRAULIC SUPPORT WITH SINGLE CLEARANCE}

The key to the dynamic analysis of the hydraulic support with clearance between the rear linkage and base is to establish the clearance contact force model and simulate the hydraulic support model. The contact force model of the single clearance between the rear linkage and base can be described by the Lancarani- 
Nikravesh contact force model and the developed nonlinear friction model. To simulate the contact force model between the shaft and bearing more realistically, the material of each part of the hydraulic support and the shaft should be defined. Here, the components of the hydraulic support are defined as steel material, and the material of shaft is $35 \mathrm{CrMo}$, their material properties are shown in Table 1.

Table 1. Material properties of hydraulic support and shaft

\begin{tabular}{lccc}
\hline Material & $\begin{array}{c}\text { Density } \\
{\left[\mathrm{kg} \times \mathrm{mm}^{-3}\right]}\end{array}$ & $\begin{array}{c}\text { Elastic modulus } \\
{[\mathrm{MPa}]}\end{array}$ & $\begin{array}{c}\text { Poisso's } \\
\text { ratio }\end{array}$ \\
\hline Steel & $7.801 \times 10^{-6}$ & $2.07 \times 10^{5}$ & 0.29 \\
\hline $35 \mathrm{CrM0}$ & $7.850 \times 10^{-6}$ & $2.06 \times 10^{5}$ & 0.3 \\
\hline
\end{tabular}

Each part of hydraulic support is affected by the clearance between the rear linkage and base. This paper focuses on the influence of the clearance on the working performance of the hydraulic support

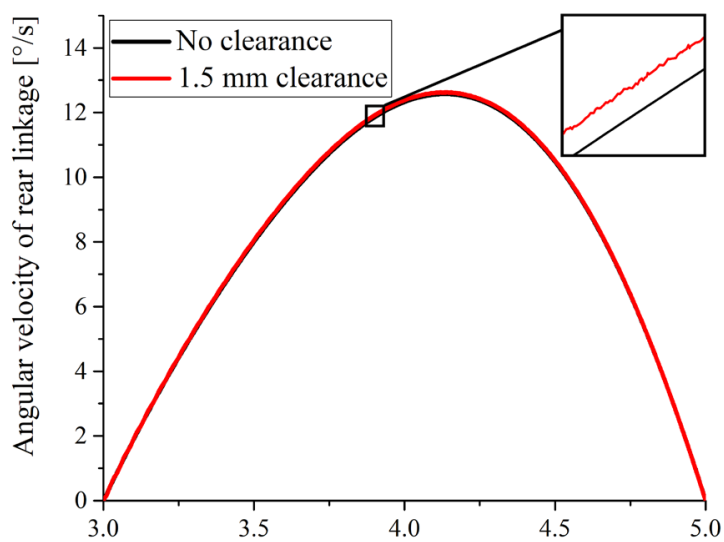

a)

Time $[\mathrm{s}]$

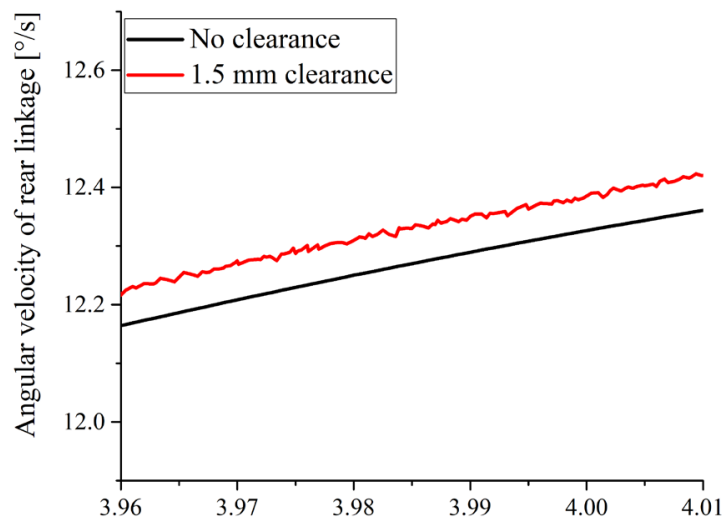

c)

Time $[\mathrm{s}]$ during its rising process. To simulate the rising action of hydraulic support, the driving of front and rear columns is established based on step function, the tail beam jack is kept still, and the influence of plug plate and plug plate jack are ignored. Through the above driving and clearance contact force model, the dynamic models of the hydraulic support with single clearance between the rear linkage and base are analysed.

\section{ANALYSIS OF THE INFLUENCE OF CLEARANCE ON HYDRAULIC SUPPORT}

Combined with the previous research results on clearance, it can be seen that the existence of clearance will cause the performance of mechanical systems to decline. However, due to the lack of relevant research, the influence of the clearance between the rear linkage and base on the hydraulic support remains uncertain. Therefore, this section analyses how the existence

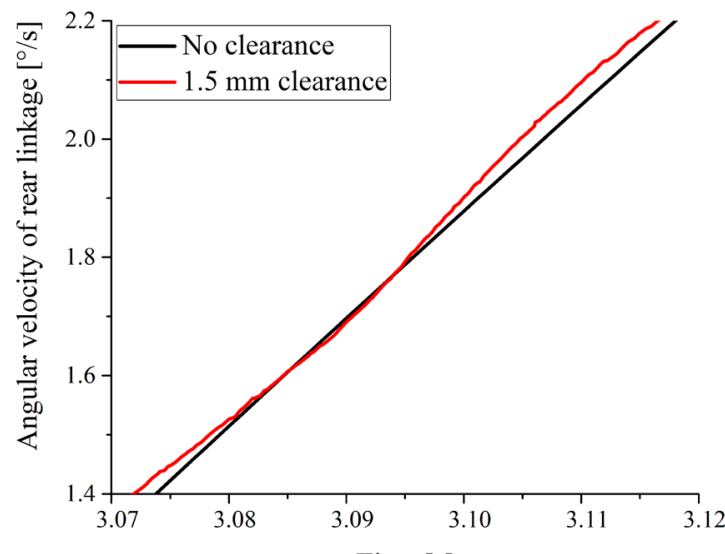

b)

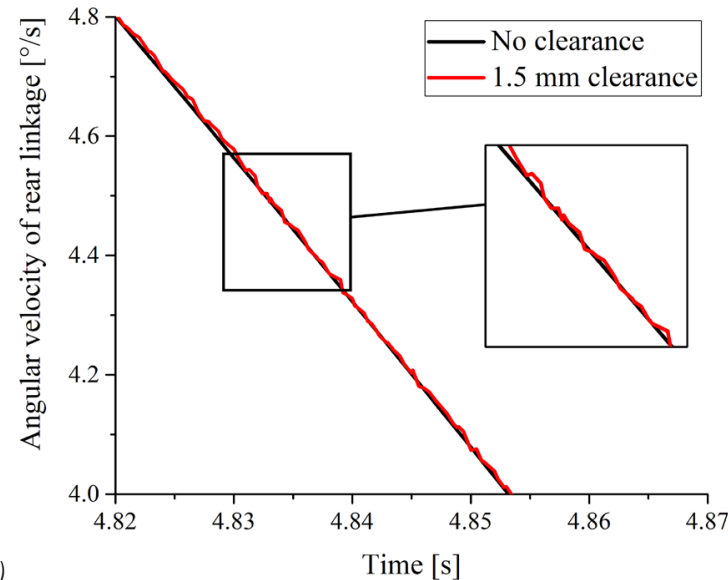

Fig. 3. Dynamic performance of rear linkage with $1.5 \mathrm{~mm}$ clearance and without clearance: a) overall angular velocities of rear linkage, $b$ ) local enlarged curves of angular velocities in early stage, c) local enlarged curves of angular velocities in the middle stage, and d) local enlarged curves of angular velocities in later stage 
of clearance affects the movement and force of the hydraulic support. When there is a $1.5 \mathrm{~mm}$ clearance between the rear linkage and base, the movement and force of the rear linkage is compared with that without clearance, so as to study the influence of the clearance on the working performance of the hydraulic support.

Before the analysis of the hydraulic support with $1.5 \mathrm{~mm}$ clearance or without clearance, the stiffness coefficient of the contact between the bearing and shaft should be calculated. According to Eq. (5) and the material properties of shaft and bearing, the stiffness coefficient of shaft and bearing is 857942.947 when the clearance is $1.5 \mathrm{~mm}$. Based on the stiffness coefficient, the dynamic model of the hydraulic support with $1.5 \mathrm{~mm}$ clearance and the dynamic model of the hydraulic support without clearance are analysed. The movement and force variation curves of the rear linkage are shown in Fig. 3. Fig. 3a shows the angular velocity curve of the rear linkage when there is no clearance and when there is a $1.5 \mathrm{~mm}$ clearance between the rear linkage and base. It can be seen from the figure that the angular velocities of the rear linkage in the two cases change in the same trend, and the angular velocity curve is very similar, but there are still some differences in the local curve. Fig. $3 b$ to $d$ shows the local enlarged view of the angular velocity curve of the rear linkage in different periods during the movement process. It can be seen that compared with the angular velocity of the rear linkage without clearance, the angular velocity of the rear linkage fluctuates when there is a $1.5 \mathrm{~mm}$ clearance between the rear linkage and base, and the angular velocity of the middle stage of the rear linkage with $1.5 \mathrm{~mm}$ clearance is higher than that without clearance.

Fig. 4 shows the angular acceleration curve of the rear linkage when there is no clearance and when there is a $1.5 \mathrm{~mm}$ clearance between the rear linkage and base. It can be seen from the figure that the angular acceleration of the rear linkage has a great fluctuation when there is a $1.5 \mathrm{~mm}$ clearance between the rear linkage and base, but the change trends of the angular acceleration curve in two cases are the same. Therefore, although the clearance does not change the movement trend of the hydraulic support, it will make the movement of the hydraulic support fluctuate, resulting in the decrease of the stability during the movement of hydraulic support. Fig. 5 shows the contact force curve of the rear linkage when there is no clearance and when there is a $1.5 \mathrm{~mm}$ clearance between the rear linkage and base. This is the same as the difference of angular velocity and angular acceleration curve of the rear linkage, when there is a clearance between the rear linkage and base, the contact force at the rear linkage fluctuates greatly, but the variation trend of the contact force is the same as that without clearance. Therefore, the existence of clearance will lead to the fluctuation of contact force between the rear linkage and base during hydraulic support movement, which will seriously affect the working stability of hydraulic support and reduce the working performance of hydraulic support.

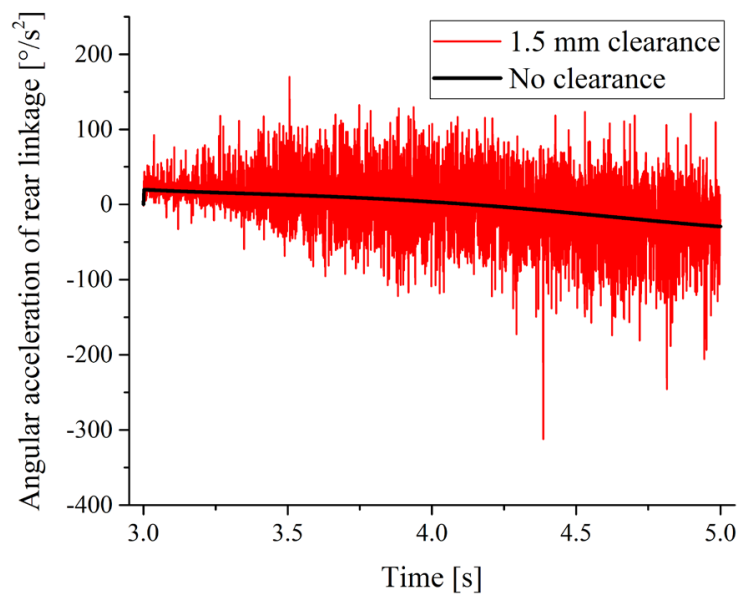

Fig. 4. Angular accelerations of rear linkage with clearance and without clearance

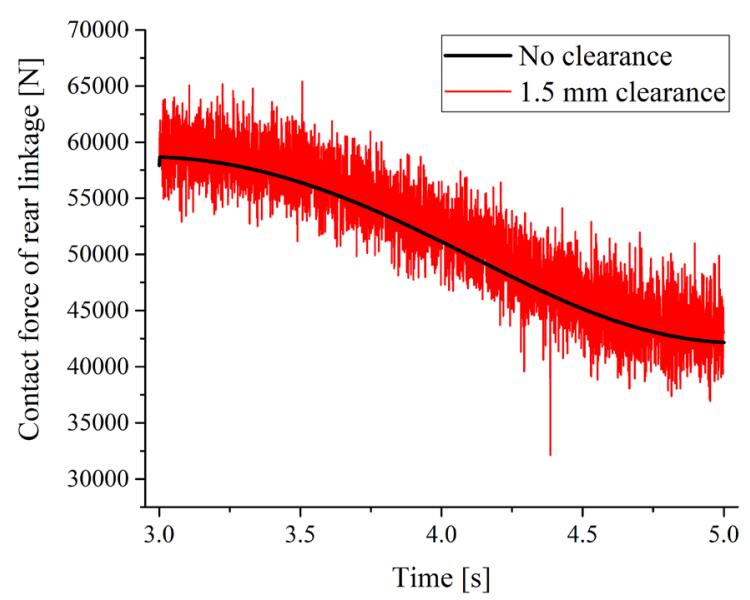

Fig. 5. Contact forces of rear linkage with clearance and without clearance

By comparing the dynamic performance of the rear linkage with and without clearance, it can be seen that the clearance has little influence on the overall change trend of the hydraulic support, but will lead to the fluctuation of the movement and force, aggravate the instability of the hydraulic support, and do great harm to the normal work of the support. Therefore, research on the clearance is very important for improving the working performance and the safety of the hydraulic support. 


\section{ANALYSIS OF THE INFLUENCE OF CLEARANCE SIZE ON HYDRAULIC SUPPORT}

Through the dynamic comparative analysis of the hydraulic support with clearance or without clearance, it can be seen that the clearance affects the stability of the hydraulic support, leading to the decline of the working performance of the hydraulic support. In order to study the influence of clearance size on the hydraulic support, the dynamic models of hydraulic support with different clearance sizes between the rear linkage and base are established. The clearance dimensions of the rear linkage are taken as $0.5 \mathrm{~mm}$, $1.0 \mathrm{~mm}, 1.5 \mathrm{~mm}$ and $2.0 \mathrm{~mm}$. According to Eq. (5), the stiffness coefficients of shaft and bearing are calculated, as shown in Table 2. Based on the stiffness coefficient of different clearance sizes, the dynamic analysis of hydraulic support with different clearance

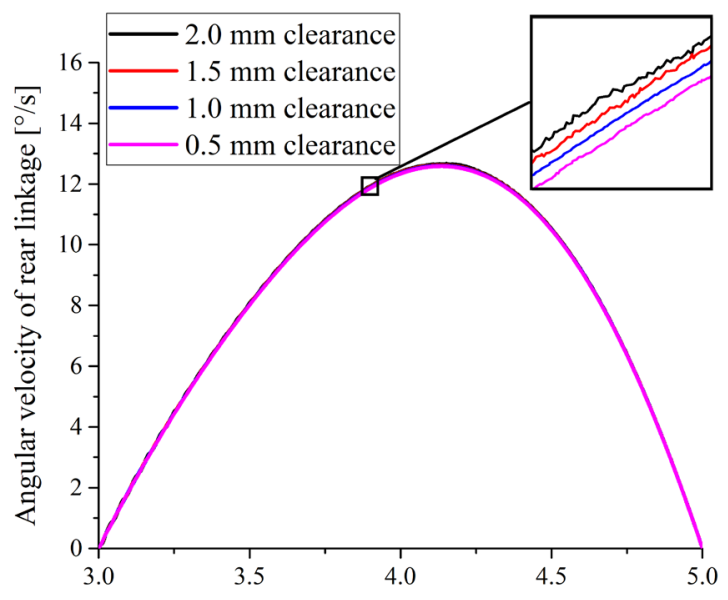

a)

Time $[\mathrm{s}]$

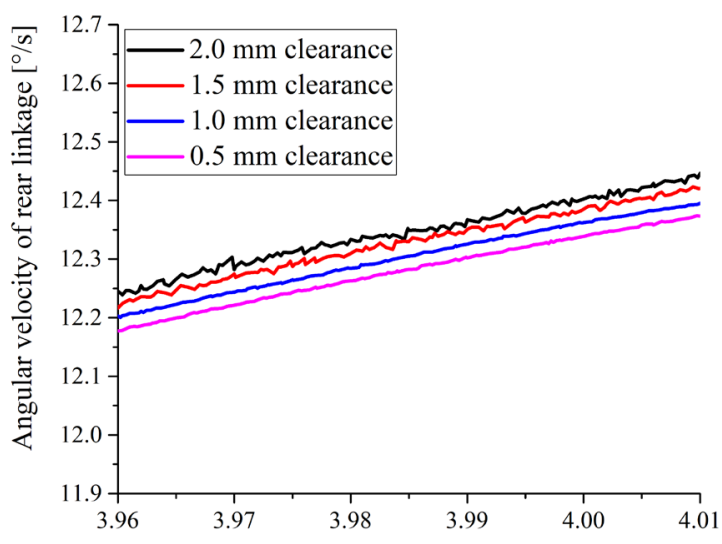

c)

Time [s] sizes between the rear linkage and base are carried out, and the influence of clearance size on the movement, force and posture of the hydraulic support is studied.

Table 2. Stiffness coefficient of different clearance

\begin{tabular}{ccc}
\hline $\begin{array}{c}\text { Clearance radius } \\
{[\mathrm{mm}]}\end{array}$ & $\begin{array}{c}\text { Shaft radius } \\
{[\mathrm{mm}]}\end{array}$ & Stiffness coefficient \\
\hline 0.5 & 65.0 & 861300.557 \\
\hline 1.0 & 64.5 & 859629.849 \\
\hline 1.5 & 64.0 & 857942.947 \\
\hline 2.0 & 63.5 & 856239.607 \\
\hline
\end{tabular}

\subsection{The Influence of Clearance Size on the Movement of Hydraulic Support}

To study the influence of clearance size on the movement of hydraulic support, the angular velocity and angular acceleration curves of the rear linkage

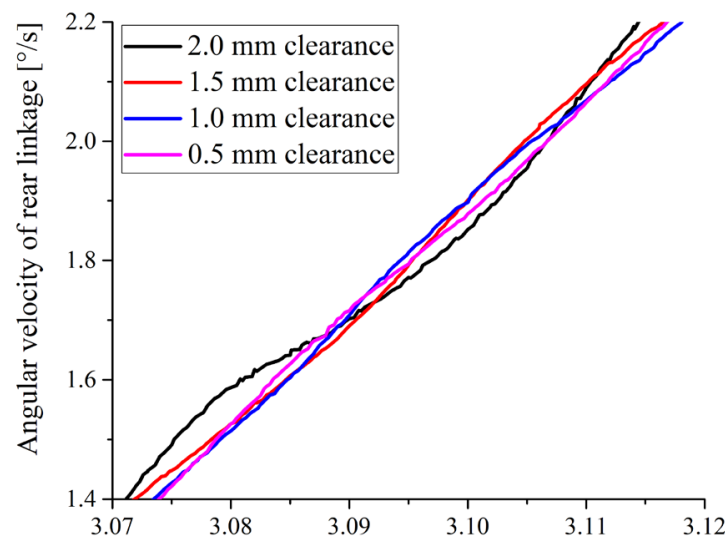

b)

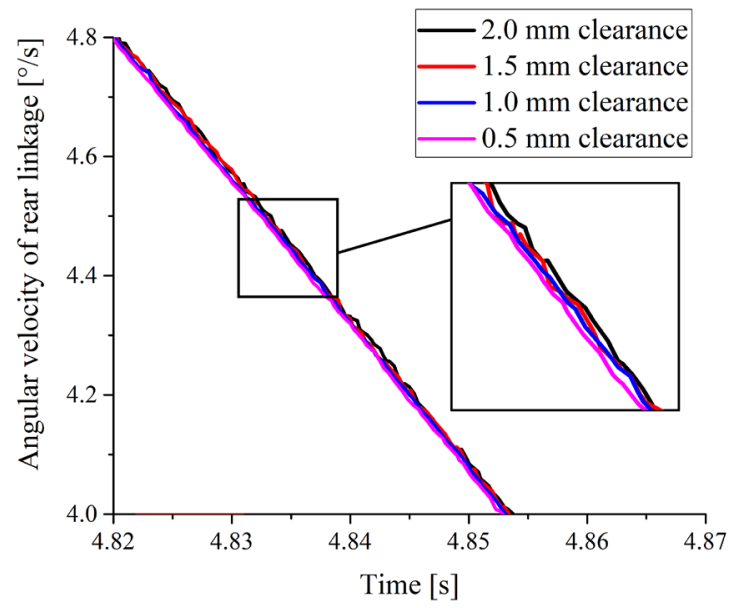

Fig. 6. Angular velocities of rear linkage with different clearance size; a) overall angular velocities of rear linkage; b) local enlarged curves of angular velocities in early stage; c) local enlarged curves of angular velocities in the middle stage; and d) Local enlarged curves of angular velocities in later stage 
with different clearance sizes were compared. In Fig. 6a, the angular velocity of the rear linkage changes with different clearance sizes. It can be seen from the figure that the angular velocity of the rear linkage changes with time in different clearance sizes with the same trend, and clearance size has little effect on angular velocity, the angular velocity curves of the rear linkage in each situation are very similar. To analyse the impact of clearance size on the angular velocity of the rear linkage specifically, the local enlarged view of the angular velocity curves in different periods was taken for comparison. As shown in Fig. $6 \mathrm{~b}$ to $d$, the angular velocities of the rear linkage with different clearance sizes in the early and late stage are similar. However, the degree of angular velocity fluctuations is different, and the larger the clearance size is, the greater the fluctuation of angular velocity is. The numerical value and fluctuation of the angular velocity of rear linkage are different in the middle stage with different clearance sizes. The

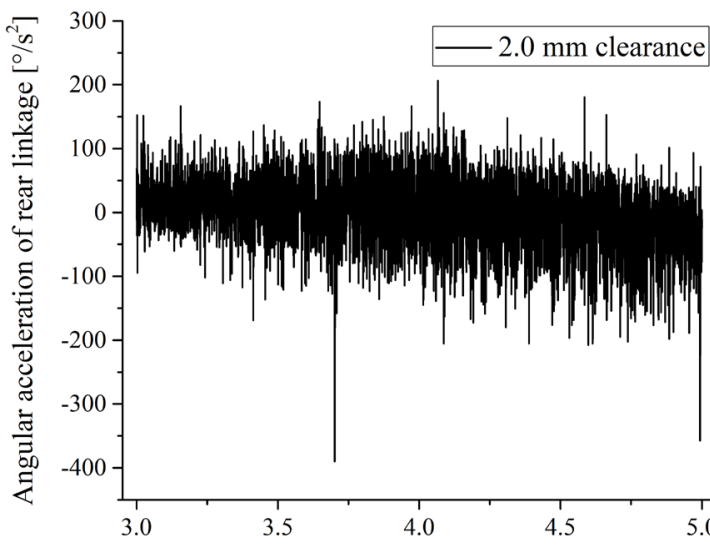

a)

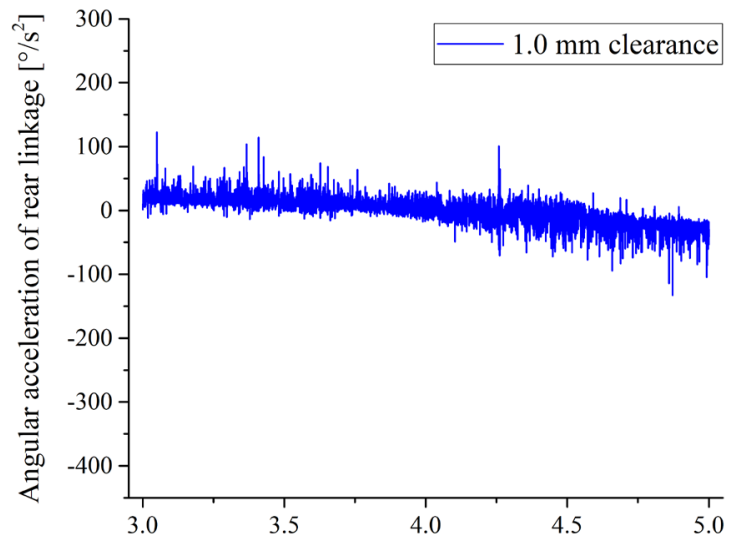

c)

Time $[\mathrm{s}]$ larger the clearance is, the larger the numerical value of angular velocity in the middle stage and the larger the fluctuation of angular velocity are.

Fig. 7 shows the angular acceleration curves of the rear linkage with different clearance sizes. It can be seen from the figure that the angular accelerations with different clearance sizes change with the same trend over time, but the fluctuation degree of angular accelerations is different, the fluctuations of the angular acceleration with the clearance of $2.0 \mathrm{~mm}$ and $1.5 \mathrm{~mm}$ are much greater than that with the clearance of $1.0 \mathrm{~mm}$ and $0.5 \mathrm{~mm}$. To further analyse the influence of clearance size on the angular acceleration of the rear linkage, the average angular acceleration values during the rising process of hydraulic supports with different clearance sizes were compared. The average angular acceleration values of $2.0 \mathrm{~mm}$ clearance was $-0.3219 \% / \mathrm{s}^{2}, 1.5 \mathrm{~mm}$ was $-0.2733 \% \mathrm{~s}^{2}, 1.0 \mathrm{~mm}$ was $-0.0515 \% \mathrm{~s}^{2}$, and $0.5 \mathrm{~mm}$ was $0.0030 \%$ / 2 respectively. By comparing the average angular acceleration of

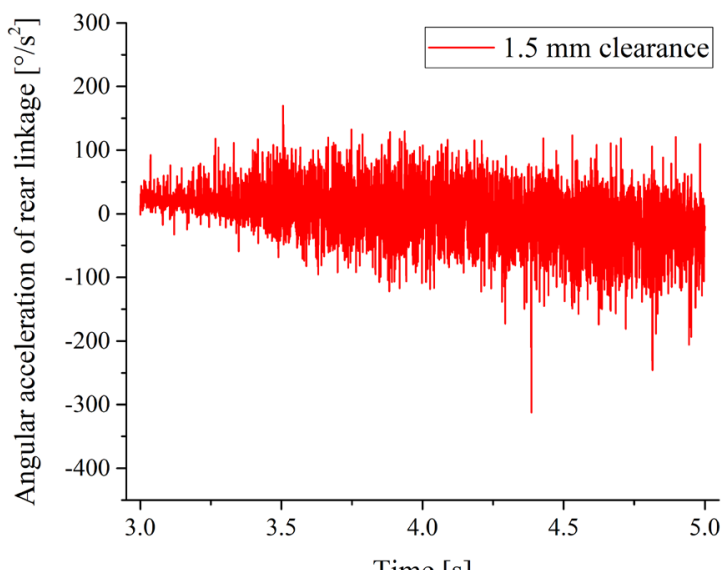

b)

Time [s]

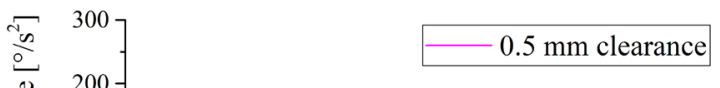

Fig. 7. Angular accelerations of rear linkage with different clearance sizes; a) $2.0 \mathrm{~mm}$ clearance, b) $1.5 \mathrm{~mm}$ clearance, c) $1.0 \mathrm{~mm}$ clearance, and d) $0.5 \mathrm{~mm}$ clearance 
the rear linkage, it can be seen that the clearance size has little influence on the numerical value of angular acceleration, and the overall movement trend of the hydraulic support is basically unchanged.

The hydraulic supports with different clearance size have the same movement trend in Figs. 6 and 7. However, the clearance size between the rear linkage and base makes the angular velocity and angular acceleration of the rear linkage fluctuate differently. The larger the clearance size is, the greater the fluctuation degree of the rear linkage movement is, and the greater the impact on the stability of the hydraulic support is, the greater the harm will be caused. It can be seen that the clearance size is an important factor affecting the movement fluctuation of the hydraulic support, so a reasonable clearance size is very important to improve the working performance of the support and reduce the operation accidents of the support.

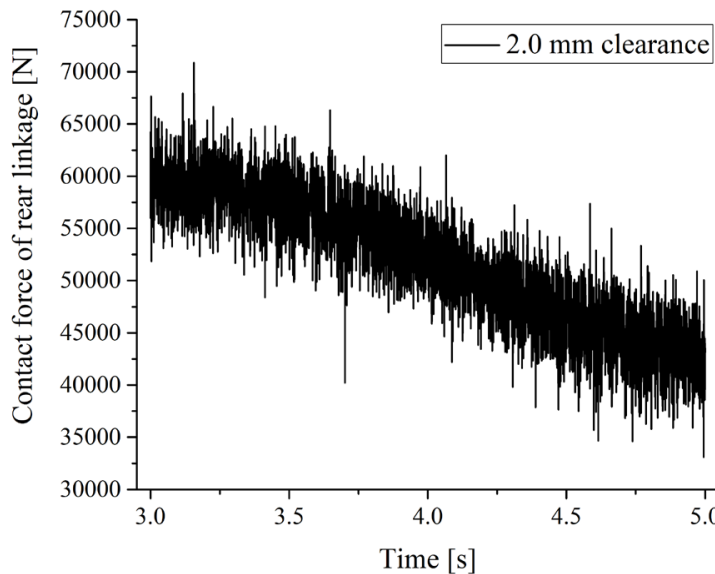

a)

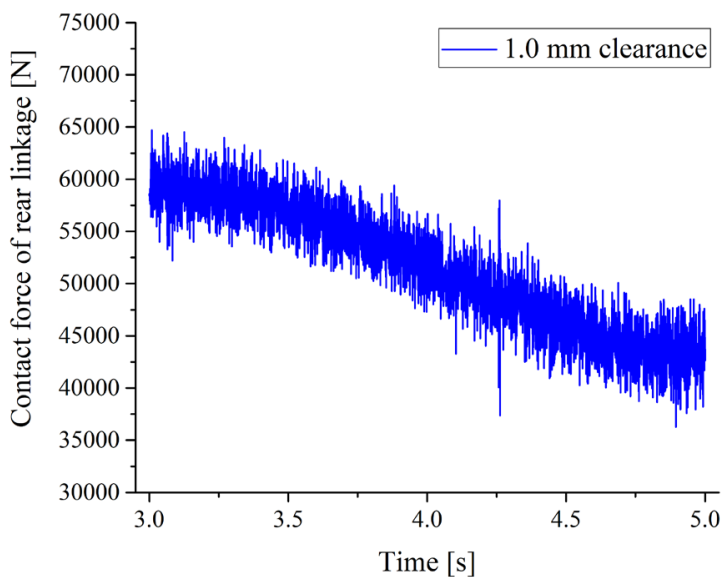

\subsection{The Influence of Clearance Size on the Force of Hydraulic Support}

To analyse the influence of the clearance size on the force of the hydraulic support, the contact forces of the rear linkage with different clearance sizes during the rising process of the hydraulic support were analysed. It can be seen from Fig. 8 that the variation trends of the contact force of the rear linkage with different clearance sizes are the same, but the fluctuations of the contact force are different. To accurately analyse the contact force of the rear linkage with different clearance sizes, the average values of the contact force in each case are taken for comparison, so as to judge the influence of the clearance size on the contact force value; the standard deviations of the contact force in each case are taken for comparison, so as to judge the influence of the clearance size on the fluctuation degree of the contact force. The mean and standard

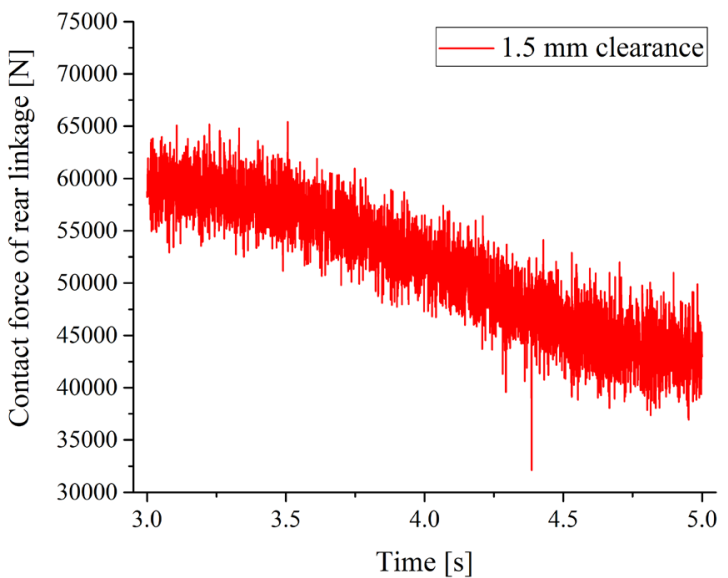

b)

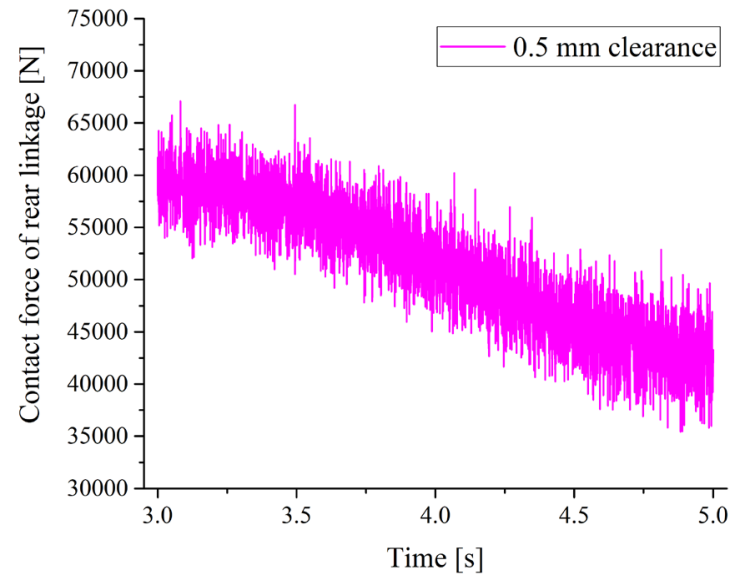

Fig. 8. Contact forces of rear linkage with different clearance sizes; a) $2.0 \mathrm{~mm}$ clearance; b) $1.5 \mathrm{~mm}$ clearance; c) $1.0 \mathrm{~mm}$ clearance; d) $0.5 \mathrm{~mm}$ clearance 
deviations of the contact force of the rear linkage are shown in Table 3.

Table 3. Average and standard deviation of contact force under different clearance sizes

\begin{tabular}{ccc}
\hline $\begin{array}{c}\text { Clearance radius } \\
{[\mathrm{mm}]}\end{array}$ & $\begin{array}{c}\text { Average of contact } \\
\text { force }[\mathrm{N}]\end{array}$ & $\begin{array}{c}\text { Standard deviation of } \\
\text { contact force }[\mathrm{N}]\end{array}$ \\
\hline 0.500 & 51375.609 & 6114.940 \\
\hline 1.000 & 51491.566 & 5938.103 \\
\hline 1.500 & 51649.027 & 6013.112 \\
\hline 2.000 & 51795.195 & 6188.895 \\
\hline
\end{tabular}

The data in Table 3 show that the average of contact force of rear linkage increases with the increase of clearance size, but the increase in the average is small. The standard deviation of the contact force is also related to the clearance size. The standard deviation of contact force decreases at first and then increases with different clearance sizes. It can be seen from the change of the mean value and standard deviation that the clearance size has an influence on the force of hydraulic support, but the influence is relatively small, and the clearance size also affects the fluctuation degree of contact force, but the fluctuation of contact force does not decrease with the decrease of clearance size. Therefore, the clearance size also has an impact on the stability of the hydraulic support force, which will affect the working performance of the hydraulic support.

\subsection{The Influence of Clearance on the Posture of Hydraulic Support}

The rear linkage, as a part of the hydraulic support four-connecting-rod structure, has an important influence on the posture of the hydraulic support. To analyse the impact of clearance on the posture of hydraulic support, this section selects the movement trajectory of the endpoint of the top beam when there is no clearance and when there are different clearance sizes, obtains the impact of different clearances on the end distance between roof bar end and coal wall. It can be seen from Figs. 9 and 10 that the existence of the clearance changes the movement state of the fourbar structure of the hydraulic support, which causes the movement trajectory of the endpoint of the top beam to shift in the direction of the rear linkage during support's rising process.

Moreover, the larger the clearance size, the larger the distance of the movement trajectory of the rear linkage. In addition, it can be seen from the figure that the movement range of the end point of the top beam is similar in the horizontal direction when there is no clearance and when the clearance sizes are different. Therefore, the clearance and clearance size will increase the distance of the top beam end point, which reduces the stability of the support, but it has little influence on the horizontal movement range of the top beam.

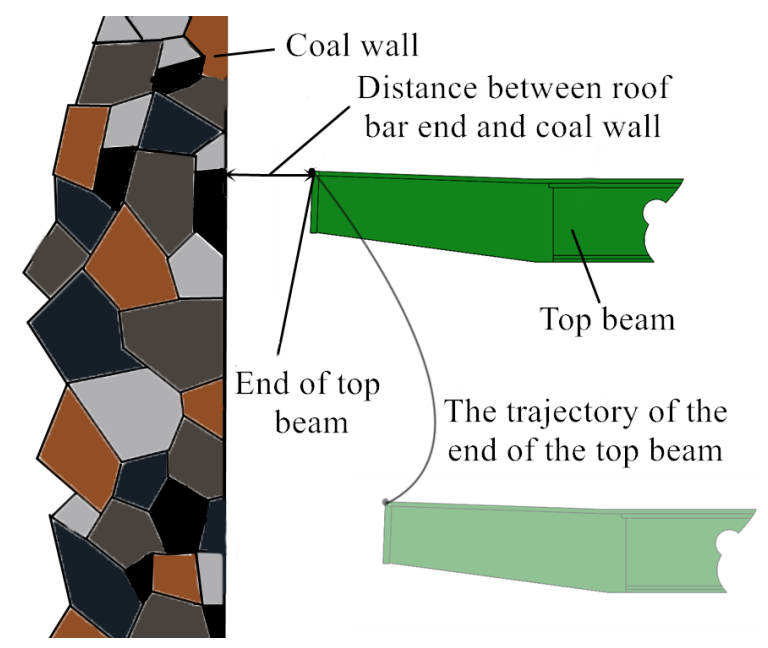

Fig. 9. Position and movement trajectory of end point

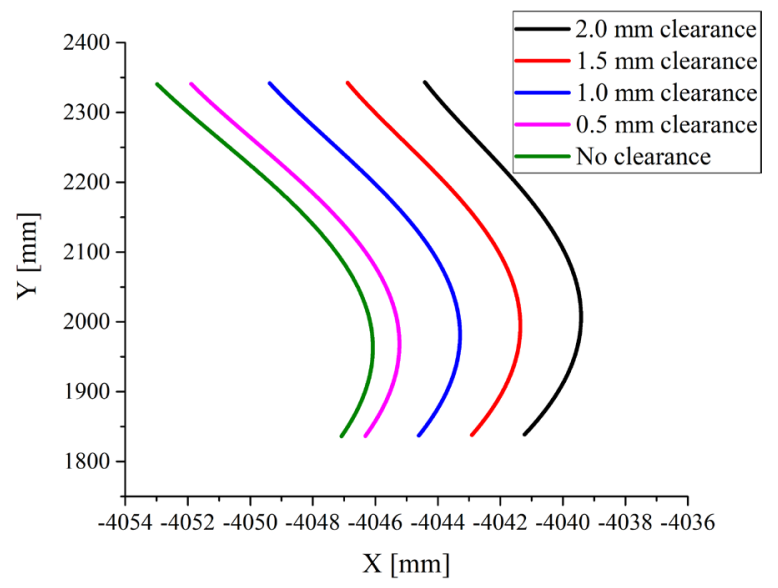

Fig. 10. Change of end point with different clearances

The front and rear columns are the main driving force source of the hydraulic support. The posture variation of the front and rear columns will have a great impact on the working performance of the hydraulic support. Therefore, the angles of the front and rear columns are defined in Fig. 12, and the variation of the angle of the front and rear columns when there is no clearance and when the clearance sizes are different are shown in Fig. 11. It can be seen from Fig. 11 that the front and rear columns deflect to the rear linkage for their horizontal angles decreasing, and the larger the clearance size is, the smaller the horizontal angles of the front and rear columns are. 

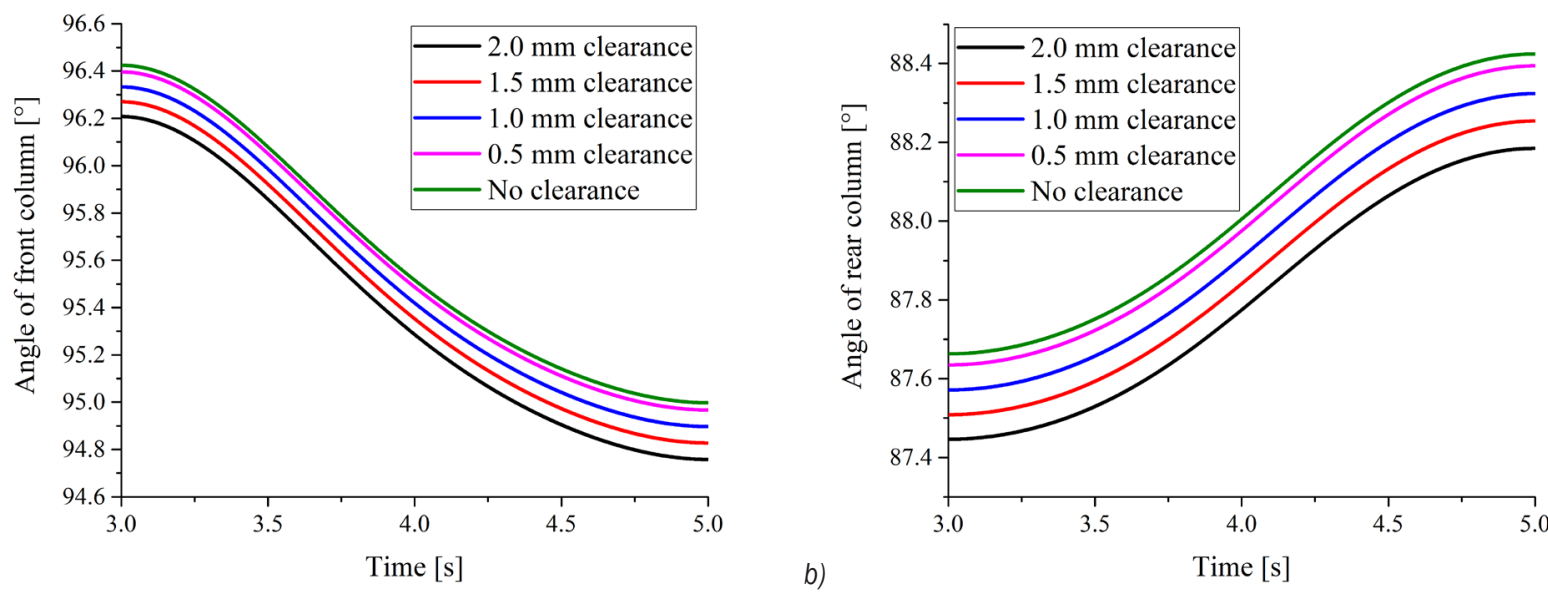

Fig. 11. Angle change of columns with different clearances; a) angle change of front column; and b) angle change of rear column

Although the deflection direction of the front and rear columns is the same, the effects on the front and rear columns are completely opposite, the clearance makes the front column tend to the vertical direction, which enhances its supporting capacity, and the clearance causes the rear column to deviate from the vertical direction, which decreases the support capacity of the rear column. Compared with the former results, the clearance not only changes the posture of the hydraulic support, but also affects the force situation of the hydraulic support and the difference of posture increases with the clearance size.

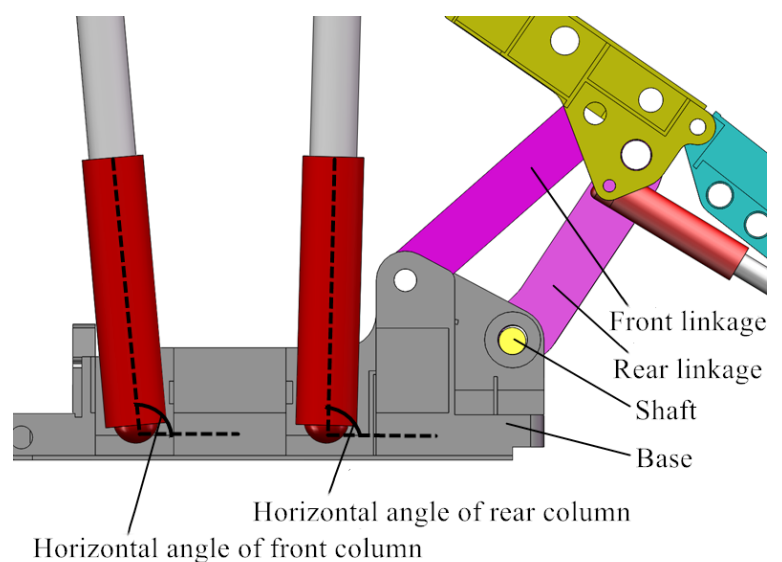

Fig. 12. Horizontal angle of front and rear columns

\section{THE INFLUENCE OF THE OIL INLET DRIVE MODE ON HYDRAULIC SUPPORT WITH SINGLE CLEARANCE}

Impact is one of the most serious factors affecting clearance. During the movement of hydraulic support, different oil inlet drive modes have different impacts on hydraulic support, and the existence of the clearance makes the impacts on hydraulic support more obvious. To study the influence of different oil inlet drive modes on the hydraulic support with clearance between the rear linkage and base, two different oil inlet drive modes are adopted for dynamic models. Fig. 13a shows the displacement curves of the front and rear columns of the hydraulic support in two oil inlet drive modes. In the figure, the oil inlet drive mode 1 is the uniform oil inlet drive model, the front and rear columns move directly at a speed from stationary without transition, which belongs to the direct oil inlet drive mode with impact, and oil inlet drive mode 2, which established by step function, makes the extension displacement of front and rear columns change smoothly with gently variable speed. Step function is a common description of the driver, and the expression of oil inlet drive mode 2 is STEP(TIME, 0,0,3,0) + STEP(TIME,3,0,5,500).

\section{CONCLUSIONS}

The dynamic analysis of the hydraulic support with clearance between the rear linkage and base was carried out based on the Lancarani-Nikravesh contact force model. The dynamic performance of the rear linkage of hydraulic support with and without clearance was compared. The movement and force changes of hydraulic support with different clearance size and oil inlet drive mode were analysed, and the influence of clearance and clearance size on the posture of hydraulic support was studied. Comparing the dynamic characteristics of hydraulic support under different factors, the main results are as follows:

(1) Clearance is an important factor affecting the stability of hydraulic support. Compared with the hydraulic support without clearance, the existence 


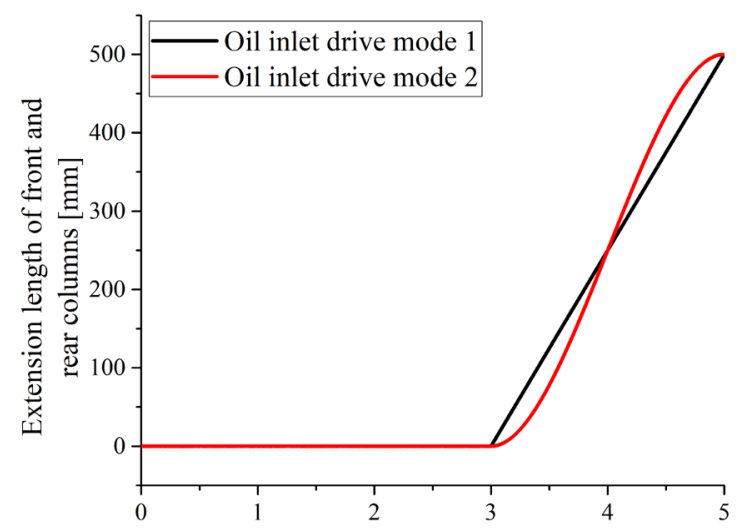

a)

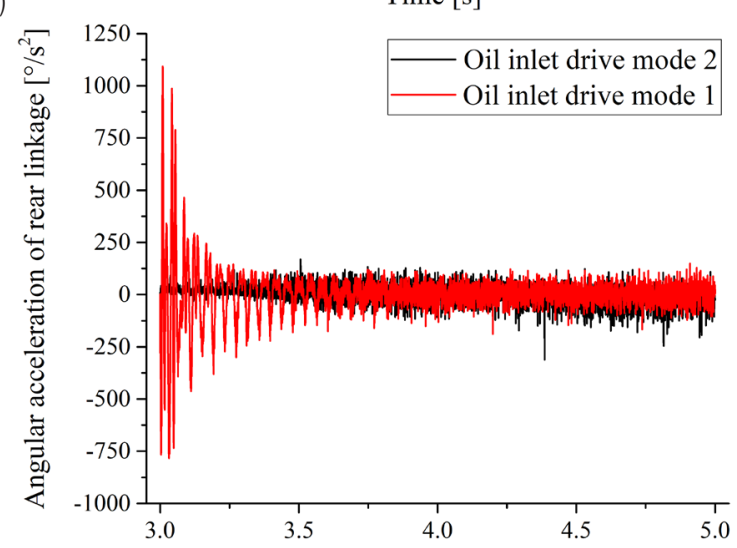

C)

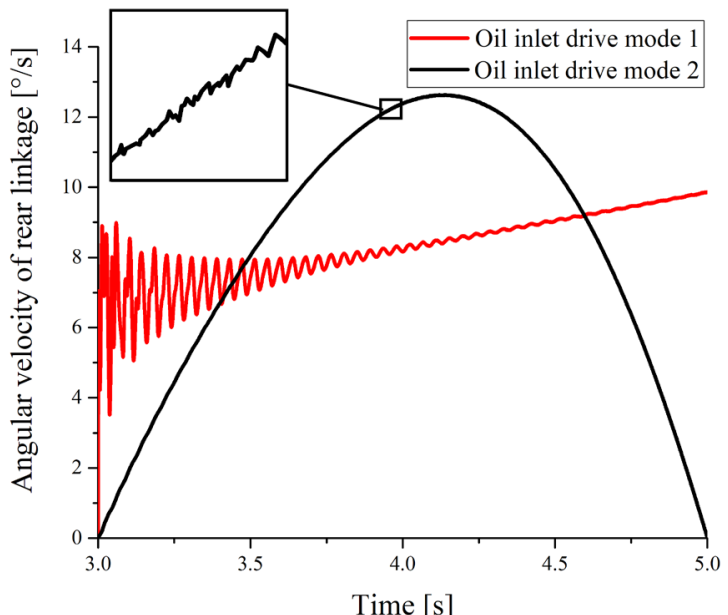

b)

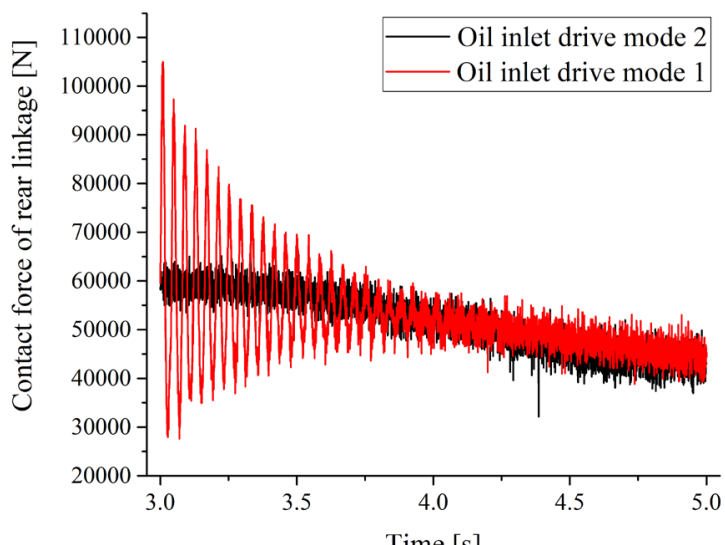

d)

Time $[\mathrm{s}]$

Fig. 13. Dynamic performance of rear linkage during different oil inlet drive modes; a) displacements of front and rear columns during different oil inlet drive modes; b) angular velocities of rear linkage; c) angular accelerations of rear linkage; and d) contact forces of rear linkage

of clearance makes the movement and force of the hydraulic support fluctuate, which reduces the working stability of the hydraulic support.

(2) Clearance size is an important point when studying the influence of clearance on hydraulic support. The clearance size changes the movement and force fluctuation of hydraulic support. The reasonable clearance size can improve the stability of hydraulic support.

(3) Different oil inlet drive modes have different responses to hydraulic supports with clearance. A smooth oil inlet drive mode can reduce the fluctuation caused by clearance; otherwise, it will affect the stable operation of hydraulic support.

(4) The clearance changes the posture of the hydraulic support. The clearance between the rear linkage and base changes the posture of the driving columns and changes the working performance of the columns.
To summarize, the clearance and clearance size affect the movement and force of the hydraulic support, change the posture of the support, and the response of clearance to different oil inlet drive modes is very different, which reduces the stability of the hydraulic support, and even affects the normal work of hydraulic support. Therefore, the clearance is an important part of the analysis of hydraulic support, which is of great significance to the further study of hydraulic support.

\section{ACKNOWLEDGEMENTS}

This work was supported by National Natural Science Foundation of China (Grant No. 51974170) and Special Funds for Climbing Project of Taishan Scholars. Shandong University of Science and Technology and Shandong Normal University 
contributed to the work equally and should be regarded as co-first units.

\section{REFERENCES}

[1] Lian, Z.S., Yuan, X., Gao, F. (2020). Networked intelligent sensing control method for hydraulic support. Acta Coal Sinica, vol. 45, no. 6, p. 2078-2089, Dol:10.13225/j.cnki.jccs. ZN20.0361. (in Chinese)

[2] Fang, X.Q., Liang, M.F., Li, S. (2020). Key technology of multi parameter accurate perception and safety decision in intelligent working face. Acta Coal Sinica, vol. 45, no. 1, p. 493-508, D0l:10.13225/j.cnki.jccs.YG19.1604. (in Chinese)

[3] Du, Y.B. (2017). Supporting condition acquisition and fuzzy comprehensive evaluation method for hydraulic support. Acta Coal Sinica, vol. 42, p. 260-266, Dol:10.13225/j.cnki. jccs.2016.1467. (in Chinese)

[4] Bao, Y.S. (2020). Research on intelligent control key technology of fully mechanized top coal caving face in extra thick coal seam. Coal Science and Technology, vol. 48, no. 7, p. 55-61, Dol:10.13199/j.cnki.cst.2020.07.004. (in Chinese)

[5] You, X.S., Wan, H., Wei, W.Y. Research on support tracking automation based on genetic algorithm and BP neural network, from http://kns.cnki.net/kcms/detail/11.2402. TD.20200527.1115.002.html, accessed on 2020-06-06. (in Chinese)

[6] Wang, G.F., Hu, X.B., Liu, X.H. Yu, X., Liu, W.C., Lv, Y., Zheng, Z. (2020). Adaptability analysis of four column hydraulic support in large mining height caving mining face of kilometer deep mine. Acta Coal Sinica, vol. 45, no. 3, p. 865-875 DOI:10.13225/j.cnki.jccs.SJ19.1516. (in Chinese)

[7] Pan, Y.S., Xiao, Y.H., Li. G.Z. (2020). Research and application of roadway anti scour hydraulic support. Acta Coal Sinica, vol. 45, no. 1, p. 90-99, D0I:10.13225/j.cnki.jccs.YG19.1762. (in Chinese)

[8] Zeng, X.T., Meng, G.Y., Zheng, K. (2019). Force transmission analysis of sliding block-type hydraulic support under impact loads. International Journal of Simulation Modelling, vol. 18, no. 1, p. 100-111, D0I:10.2507/IJSIMM18(1)466.

[9] Flores, P. (2010). A parametric study on the dynamic response of planar multibody systems with multiple clearance joints. Nonlinear Dynamics, vol. 61, p. 633-653, D0l:10.1007/ s11071-010-9676-8.

[10] Flores, P. Koshy, C.S., Lankarani, H.M., Ambrósio, J. (2011). Numerical and experimental investigation on multibody systems with revolute clearance joints. Nonlinear Dynamics, vol. 65, p. 389-398, Dol:10.1007/s11071-010-9899-8.

[11] Li, X.F., Wu, S.J., Li, X. (2019). Study on chaotic characteristics of spring operating mechanism considering joint clearance. Journal of Huazhong University of science and Technology (Natural Science Edition), vol. 47, no. 4, p. 44-49, D0l:10.13245/j.hust.190408. (in Chinese)

[12] Pereira, C., Flores, P., Ramalho, A., Ambrósio, J, (2010). The influence of contact model, friction and lubrication on the dynamics of cylindrical clearance joints. 10th International Conference on Computational Structures Technology, art. ID 218, DOI:10.4203/ccp.93.218.
[13] Li, S., Xu, J., Zhao, J. (2018). Research on dynamic characteristic of connecting rod with joint clearance. $6^{\text {th }}$ International Conference on Mechanical Engineering, Materials Science and Civil Engineering, Dol:10.1088/1757899X/542/1/012081.

[14] Li, Y.B., Xu, T.T., Zheng, H., Wang Z.S. (2020). Dynamic characteristics of spatial parallel mechanism with spherical pair clearance. Journal of Zhejiang University (Engineering Edition), vol. 54, no. 2, p. 348-356. (in Chinese)

[15] Erkaya, S. (2012). Investigation of joint clearance effects on welding robot manipulators. Robotics and ComputerIntegrated Manufacturing, vol. 28, no. 4, p. 449-457, DOI:10.1016/j.rcim.2012.02.001.

[16] Erkaya, S. (2018). Effects of joint clearance on the motion accuracy of robotic manipulators. Strojniški vestnik Journal of Mechanical Engineering, vol. 64, no. 2, p. 82-94, DOI:10.5545/sv-jme.2017.4534.

[17] Bai, Z.F., Jiang, X., Li, F., Zhao, J.J., Zhao, Y. (2018). Reducing undesirable vibrations of planar linkage mechanism with joint clearance. Journal of Mechanical Science and Technology, vol. 32, p. 559-565, DOl:10.1007/s12206-018-0103-7.

[18] Wang, X. P, Liu, G., Ma, S., Tong, R.T., Xue, Y.M. (2017). Effects of clearance joint on impact dynamic characteristics of planar mechanisms. Journal of Vibration and Shock, vol. 36, no. 17, p. 74-78, D0l:10.13465/j.cnki.jvs.2017.17.012. (in Chinese)

[19] Wang, X., Lin, W., Ji, X., Gaou, Z., Bai, X., Guo, Y. (2019). Dynamic analysis of a planar multibody system with multiple revolute clearance joints. Proceedings of the Institution of Mechanical Engineers, Part C: Journal of Mechanical Engineering Science, vol. 233, no. 10, p. 3429-3443, Dol:10.1177/0954406218819022.

[20] Matekar, S.B, Fulambarkar, A.M. (2020). Displacement analysis of slider in slider-crank mechanism with joint clearance. Australian Journal of Mechanical Engineering. DOI:10.1080/14484846.2020.1763547.

[21] Tajaril, M.J., Pedrammehr, S., Chalak Qazani, M.R., Nategh, M.J. (2017). The effects of joint clearance on the kinematic error of the hexapod tables. $5^{\text {th }}$ RSI International Conference on Robotics and Mechatronics p. 39-44, D0l:10.1109/ ICRoM.2017.8466132.

[22] Xu, C., Dong, H., Xu, S., Wu, Y., Wang, C. (2017). Study and experiment on positioning error of SCARA robot caused by joint clearance. 10th International Conference on Intelligent Robotics and Applications, vol. 10463, Dol:10.1007/978-3319-65292-4_14.

[23] Gu, Y., Zhang, Y., Zhao, J., Yan, S.Z. (2019). Dynamic characteristics of free-floating space manipulator with joint clearance. Journal of Mechanical Engineering, vol. 55, no. 3, p. 99-108, DOI:10.3901/JME.2019.03.099.

[24] Huang, J.F., Cai, Y.L., Chen. J.Y. (2019). Kinematic accuracy analysis of 3-RRR mechanism considering clearance and member flexibility. Machine Tool and Hydraulic, vol. 47, no. 3, p. 3-8, DOl:10.3969/j.issn.1001-3881.2019.03.002. (in Chinese)

[25] Hou, Y.L., Zhao, L.J., Qi, X.F., Zeng, D.X. (2019). Dynamic simulation of a flexible parallel mechanism with clearance. Journal of Yanshan University, vol. 43, no. 6, p. 485-496, Dol: 10.3969/j.issn.1007-791X.2019.06.003. (in Chinese) 
[26] Zhang, X., Zhang. X. (2017). Minimizing the influence of revolute joint clearance using the planar redundantly actuated mechanism. Robotics and Computer-Integrated Manufacturing, vol. 46, p. 104-113, D0l:10.1016/j. rcim.2017.01.006.

[27] Erkaya, S. (2018). Clearance-induced vibration responses of mechanical systems: computational and experimental investigations. Journal of the Brazilian Society of Mechanical Sciences and Engineering, vol. 40, D0I:10.1007/s40430-0181015-x.

[28] Erkaya, S. (2019). Determining power consumption using neural model in multibody systems with clearance and flexible joints. Multibody System Dynamics, vol. 47, p. 165-181, DOI:10.1007/s11044-019-09682-4.

[29] Chen, K., Zhang, G.J., Wu, R., Wang, L., Zheng, H.M., Chen, S.H. (2019). Dynamic analysis of a planar hydraulic rock-breaker mechanism with multiple clearance joints.
Shock and Vibration, vol. 2019, art. ID 4718456, DOl:10.1155/2019/4718456.

[30] Tian, Q., Flores, P., Lankarani. H.M. (2018). A comprehensive survey of the analytical, numerical and experimental methodologies for dynamics of multibody mechanical systems with clearance or imperfect joints. Mechanism and Machine Theory, vol. 122, p. 1-57, D0l:10.1016/j. mechmachtheory.2017.12.002.

[31] Edler, J., Tic, V., Lovrec, D. (2019). 1-D simulation model of a progressive flow controller for hydrostatic bearings. International Journal of Simulation Modelling, vol. 18, no. 2, p. 267-278, D0I:10.2507/IJSIMM18(2)472.

[32] Erkaya, S., Uzmay, I. (2012). Effects of balancing and link flexibility on dynamics of a planar mechanism having joint clearance. Scientia Iranica, vol. 19, no. 3, p. 483-490, DOI:10.1016/J.scient.2012.04.011. 